\title{
Coexposure to toluene and p-xylene in man: central nervous functions
}

\author{
B ANSHELM OLSON, F GAMBERALE, A IREGREN
}

From the Psychophysiological Unit, Research Department, National Board of Occupational Safety and Health, S- 17184 Solna, Sweden

ABSTRACT Sixteen men were studied in an exposure chamber to assess the effect of four hours' exposure to toluene $\left(3.25 \mathrm{mmol} / \mathrm{m}^{3}\right)$, xylene $\left(2.84 \mathrm{mmol} / \mathrm{m}^{3}\right)$, a mixture of toluene and xylene $\left(2 \cdot 20+0.94 \mathrm{mmol} / \mathrm{m}^{3}\right)$, and a control condition. With the aid of microcomputers, subjects performed tests of simple reaction time, short term memory, and choice reaction time immediately after entering the chamber, after two, and after four hours' exposure. The results indicate that the performance on the tests was unaffected by exposure. In the light of this result the risk of an acute effect on central nervous functions after exposure for four hours at concentrations that do not exceed the Swedish threshold limit values was considered to be minimal.

Studies of the long term effects of solvents on exposed groups of workers have shown indications of reduced performance in tests of various psychological functions. ${ }^{1-10}$ Investigations of spray painters and printers have suggested that the effects found are partly the result of potentiating interaction in connection with simultaneous exposure to several solvents. ${ }^{1-13}$ Since several of the most common solvents, including toluene and xylene, are metabolised by the same enzyme system, interaction of this kind is theoretically possible. ${ }^{1415}$ Animal studies, for example in rabbits, have shown that simultaneous exposure to two solvents (styrene and trichlorethylene) caused disruptions of the balance system at concentrations only $10 \%$ of those producing disruptions in exposure to either solvent on its own. ${ }^{16}$

Several laboratory studies have been undertaken in recent years of the acute effects on performance in psychological tests of exposure to toluene and xylene respectively. ${ }^{17-20}$ These studies have made it possible to assess the risks of acute effects resulting from exposure to eithr of these solvents.

As regards exposure to toluene at rest, for example, Gamberale and Hultengren found impaired performance in tests of simple and choice reaction time at a concentration of $300 \mathrm{ppm}\left(12 \cdot 2 \mathrm{mmol} / \mathrm{m}^{3}\right){ }^{17}$ Gamberale et al have also made an experimental study of the effects of exposure to xylene on central nervous functions. ${ }^{18}$ With exposures up to 1300

Received 5 December 1983

Accepted 30 January 1984 $\mathrm{mg} / \mathrm{m}^{3}\left(12.3 \mathrm{mmol} / \mathrm{m}^{3}\right)$ for 70 at minutes rest, performance was not found to be affected. When solvent uptake was increased by introducing physical work on a bicycle ergometer $(100 \mathrm{~W})$, impaired performances were obtained in complex reaction time tests and memory tests. Savolainen et al found similar effects after 5-6 hours' exposure to $4 \cdot 1 \mathrm{mmol} /$ $\left.\mathrm{m}^{3}\right) .^{19}$

Few experiments have been reported, however, in which simultaneous exposure to two or more solvents has been studied with regard to possible effects on behavioural performance even though exposure to a mixture of solvents is common in industry. In an investigation of the effects of simultaneous exposure to xylene and trichloroethane, Savolainen et al found no effects of $200 \mathrm{ppm}(8 \cdot 2$ $\left.\mathrm{mmol} / \mathrm{m}^{3}\right)$ xylene or $200 \mathrm{ppm}\left(8.1 \mathrm{mmol} / \mathrm{m}^{3}\right)$ trichloroethane. ${ }^{21}$ On the other hand, impaired performance was obtained after exposure to $400 \mathrm{ppm}$ $\left(16.2 \mathrm{mmol} / \mathrm{m}^{3}\right)$ trichloroethane and simultaneous exposure to trichloroethane and xylene; no interactive effects were noted, however. Windemüller and Ettema studied the effects of ethanol $(0.35 \mathrm{~g} / \mathrm{kg})$ combined with trichlorethylene 200 ppm (9.1 $\left.\mathrm{mmol} / \mathrm{m}^{3}\right) .^{22}$ They found simultaneous exposure to ethanol and trichlorethylene to have more pronounced effects than exposure to either separately. Savolainen studied the effects of exposure to ethanol $(0.4$ and $0.8 \mathrm{~g} / \mathrm{kg})$ and xylene $(6.0$ and 11.5 $\mathrm{mmol} / \mathrm{m}^{3}$ ) and to a combination of both. ${ }^{23}$ At the higher concentration of xylene, performance tended to deteriorate, and a dose related decrement in performance was observed after the consumption of 
alcohol. The combination of xylene and ethanol was found to have an additive effect.

To our knowledge, no study has been made of simultaneous exposure to toluene and xylene. The present experiment was therefore carried out to investigate the risk of acute effects from exposure to these solvents separately and in combination, at levels close to the Swedish threshold limit values.

\section{Method}

\section{SUBJECTS}

The 16 subjects, all volunteers, were employed at the National Board of Occupational Safety and Health. They were all healthy men aged between 23 and 38 (mean $=31)$ and were medically examined before the experiment. They were completely informed about the experiment, including the exposure conditions; they were not told of the sequence in which the conditions would occur, however.

\section{EXPOSURE CHAMBER}

Exposure took place in an $11.5 \mathrm{~m}^{3}$ chamber, the internal dimensions of which were $1.80 \times 2.80 \times$ $2.28 \mathrm{~m}$. The airflow to the chamber was $115 \mathrm{~m}^{3}$ an hour.

During the pilot experiments the temperature in the chamber rose, partly due to it being occupied by two people and also because of the heat generated by the microcomputers (see performance tests below). The microcomputers and an extra heat source were connected the previous night to ensure that the chamber temperature at the beginning of the experiment in the morning would be the same as had been reached during the pilot experiments. As a result, temperature fluctuations inside the chamber during the experiment did not exceed one degree.

\section{EXPERIMENTAL DESIGN}

The subjects were randomly divided into four subgroups. The sequence of the exposure conditions was balanced between the groups in accordance with a $4 \times 4$ Latin square, as shown in the table. Two subjects were studied at a time in the chamber under four experimental conditions. They were exposed to toluene, p-xylene (referred to below as xylene), a mixture of toluene and xylene, and pure air respectively. At the beginning of the control condition, isoamylacetate $\left(0.02-0.04 \mathrm{mmol} / \mathrm{m}^{3}\right)$ was administered for the first five minutes to disguise the absence of solvents. The exposure of each pair of subjects took place at the same time on the same day of the week and at intervals of 14 days.

As shown in the table the exposure concentrations were in the region of the Swedish threshold limit values, which are $300 \mathrm{mg} / \mathrm{m}^{3}\left(3.25 \mathrm{mmol} / \mathrm{m}^{3}\right)$ for toluene and $350 \mathrm{mg} / \mathrm{m}^{3}\left(3.30 \mathrm{mmol} / \mathrm{m}^{3}\right)$ for xylene. On each occasion, the subjects were exposed for four hours at rest.

During each exposure condition three different performance tests were administered when the subjects entered the chamber and after they had been exposed for two hours and four hours. On the day preceding the first condition, each subject attended a practice session during which he was carefully instructed about the various tests and the general conditions of the experiment.

During the second half of the experiment-that is, for eight subjects only - the heart rate was recorded every second minute of the performance tests.

Information about subjective reactions was collected at the end of each exposure condition. Furthermore, after the subjects had left the chamber, they were asked to which condition they thought 6 they had been subjected. The purpose of this question was to ascertain whether the masking of the control condition had been effective and how far the subjects had been able to distinguish between the three solvent conditions.

\section{PERFORMANCE TESTS}

Microcomputers (ABC80, Luxor AB, Motala, Sweden) were used to administer the performance tests during the experiment. Two sets of equipment, each comprising an ABC80 computer, a DataDisc 82 disc drive, an Epson Mx80 F/T printer, a reaction time panel with adapter, and a modified numerical keyboard were used. This equipment was positioned in front of each subject, except for the printers,

Table Experimental design for the four hour exposure to toluene, xylene, a combination of toluene and xylene, and control condition

\begin{tabular}{|c|c|c|c|c|}
\hline \multirow[t]{2}{*}{ Day } & \multicolumn{4}{|l|}{ Exposure $\left(m g / m^{3}\right)$} \\
\hline & Group $1(n=2+2)$ & Group $2(n=2+2)$ & Group $3(n=2+2)$ & Group $4(n=2+2)$ \\
\hline $\begin{array}{l}1 \\
2 \\
3 \\
4\end{array}$ & $\begin{array}{l}\text { Control air } \\
\text { Toluene } 300 \\
\text { Xylene } 300 \\
\text { Toluene }+ \text { xylene } 200+100\end{array}$ & $\begin{array}{l}\text { Toluene } 300 \\
\text { Control air } \\
\text { Toluene }+ \text { xylene } 200+100 \\
\text { Xylene } 300\end{array}$ & $\begin{array}{l}\text { Xylene } 300 \\
\text { Toluene }+ \text { xylene } 200+100 \\
\text { Control air } \\
\text { Toluene } 300\end{array}$ & $\begin{array}{l}\text { Toluene }+ \text { xylene } 200+100 \\
\text { Xylene } 300 \\
\text { Toluene } 300 \\
\text { Control air }\end{array}$ \\
\hline
\end{tabular}


which were placed outside the chamber. The printers were connected via a parallel interface to the microcomputers, and the adapters for the reaction time panel were connected to the series input.

After the practice session, the tests were entirely self administered, so that during the experiment the subjects were only instructed, by internal telephone, to start each of the tests. Subsequent instructions, test administration, data reduction, and data storage were then automatically managed by the microcomputers. The procedure was monitored on the printers by the experimenter. The tests were administered in the order stated below.

Simple reaction time-The task here was to push a button as quickly as possible when a light came on. A total of 176 stimuli were administered during 11 minutes at intervals of $3.75 \pm 1.25$ seconds. The first minute served as practice, and performance capacity was thus measured for 10 minutes. ${ }^{24}$

Memory - reproduction-In this test 17 series of alternating letters and figures were presented on the screen. The number of characters for each series was gradually increased during the test from four to eight. Each series was presented for four seconds, after which the subject was required to repeat it on the keyboard during the ensuing response time of 17 seconds. Data were analysed according to two performance criteria: the number of correctly reproduced series ( $\max 17)$ and the number of correctly reproduced elements $(\max 94)$.

Choice reaction time-A cross $(105 \times 95 \mathrm{~mm})$ having one arm slightly shorter than the others was displayed on the screen. The items here were on three levels of difficulty, the arms of the crosses having been reduced by 5,10 , or $15 \mathrm{~mm}$. The subject's task was to indicate, as rapidly as possible, which arm of the cross had been shortened. A specially designed response panel, comprising a keyboard with only five keys, made it possible for the subject to reply without having to divert his attention from the screen. The five keys comprised one centrally positioned key, which was the resting position, and four keys placed analogously in relation to the arms of the cross. Altogether, reaction times were measured for the 144 stimuli of the test, the 12 possible combinations of the direction and length of the arm being randomly distributed within each sequence of twelve stimuli. The stimuli were administered at fixed intervals of four seconds, giving a total test time of about 10 minutes.

\section{SUBJECTIVE SYMPTOMS}

Immediately before leaving the chamber, the subjects rated their condition on four seven point scales, the extremes of which were designated: alert/tired, concentrating/not concentrating, calm/under stress, and energetic/lazy. The subjects also rated the extent to which they experienced nausea, headache, or irritation in the eyes, nose, and oesophagus using four response categories: no, negligibly, slightly, quite considerably.

\section{STATISTICAL ANALYSIS}

The statistical analysis of the results of the performance tests was performed using analysis of variance. The analysis of variance model was adapted to a $4 \times 4$ Latin square design with repeated measurements. ${ }^{25}$ This analysis facilitated simultaneous testing of performance differences due to exposure, and with repeated measurements between (day sequence) and within (time of day) exposure occasions as well as some of the interactions between these sources of variation. Additional sources of variation were included in the analysis of the results from each of the reaction time tests. Thus simple reaction time was also analysed for performance differences during the test period, whereas the analysis of choice reaction time also included a test of the performance differences related to the direction and level of difficulty of stimuli.

\section{Results}

\section{SIMPLE REACTION TIME}

The analysis of the mean values in the test did not show any significant differences in performance between exposure conditions. On the other hand, significant differences were obtained both as a result of day sequence $F(3,36)=6.46 ; p<0.001$ and of varying times of day $F(2,24)=10.69 ; p<0.001$. Reaction time deteriorated both over and during experimental days (fig 1). A significant interactive effect emerged between exposure conditions and day sequence $F(6,36)=2.51 ; p<0.05$. This interactive effect reflects the fact that performance was definitely worst in the toluene condition, but only when toluene was given on the initial day of the experiment.

Otherwise the analysis showed a significant rise in reaction time over the testing time $F(9,108)=$ $16.76 ; p<0.001$; with reaction time rising gradually as testing proceeded (fig 2). As the trend analysis showed, this increase was not affected by exposure or by repetition of the test.

In addition to the reaction time means, and as a measure of stability, standard deviations were also computed for the 160 reaction times collected for each testing. There were no observed differences between exposure conditions using this performance criterion, however. Nor did any differences emerge due to day sequence. On the other hand, there was 
an increase in variation related to the time of day, $\mathrm{F}$ $(2,24)=22.91 ; p<0.001$.

\section{MEMORY REPRODUCTION}

The analysis of the memory test did not show any difference with regard to exposure, nor was performance affected by the day sequence or by the time of day when the analysis was based on the number of correctly reproduced series (fig 3 ). On the other hand, significant improvements in performance were found that related both to day sequence, $F(3,36)=$ $5.75 ; p<0.05$, and to time of day, $F(2,24)=$ $13.47 ; \mathrm{p}<0.001$ when the analysis was performed on the number of correctly reproduced elements; this is apparent in fig 4. No interaction effects were found.

\section{CHOICE REACTION TIME}

The choice reaction time test showed no differences in performance resulting from exposure although, as may be seen from fig 5 , there was a suggestion that performance improved due to day sequence, but this trend was not significant. Nor was there any systematic change in relation to time of day, and there were no demonstrable interactive effects.

The results described above were not altered by the analysis of performance differences with reference to direction and difficulty of stimuli. Naturally, performance deteriorated as the level of difficulty increased. The results were also influenced by the direction, in such a way that performance was worst for stimuli directed downwards and to the right. These characteristics of the test, however, did not interact with exposure.

\section{HEART RATE}

Heart rate was measured in half the subjects $(n=8)$ during the performance tests. It did not differ from one exposure condition to another; instead the average was stable in the region of 71 beats/minute. Heart rate changed significantly in relation to time of day $F(2,8)=27.94 ; p<0.001$, in such a way that it was highest during the first round of tests and lowest in the second. On the other hand, there were no effects due to day sequence, nor were there any demonstrable interactive effects.

There were, however, clear differences in heart rate between the various performance tests. Thus the subjects displayed by far the highest heart rate during the memory test, while the simple reaction time test yielded the lowest rate.

\section{SUBJECTIVE SYMPTOMS}

The results obtained from the self rating questionnaires showed no differences whatsoever as regards exposure conditions or experimental days. The

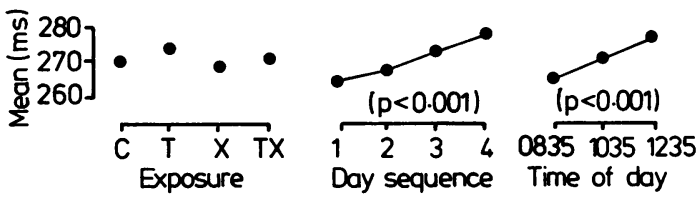

Fig 1 Mean performance in simple reaction time test as a function of exposure, day sequence, and time of day.

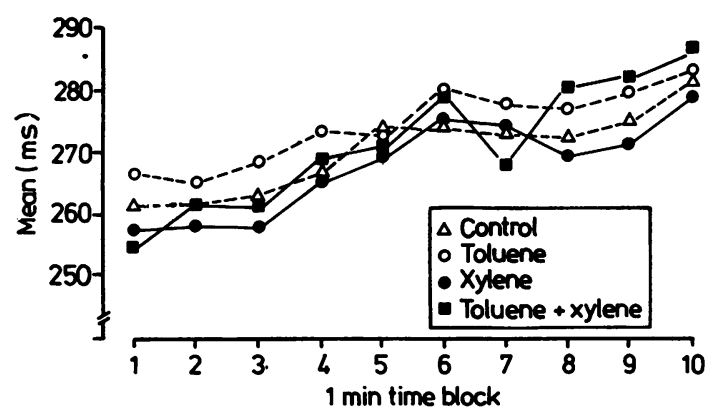

Fig 2 Mean performance in simple reaction time test for different experimental conditions as a function of time on task (1 minute time blocks).

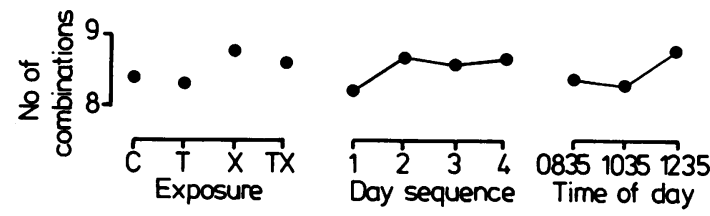

Fig 3 Mean performance in memory reproduction test (number of correctly reproduced series) as a function of exposure, day sequence, and time of day.

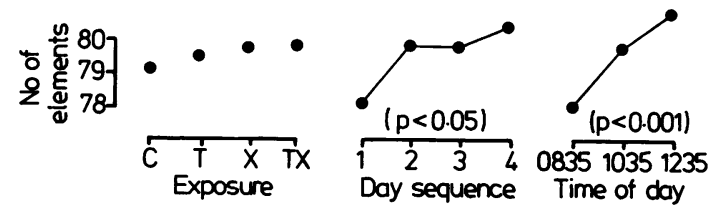

Fig 4 Mean performance in memory reproduction test (number of correctly reproduced elements) as a function of exposure, day sequence, and time of day.

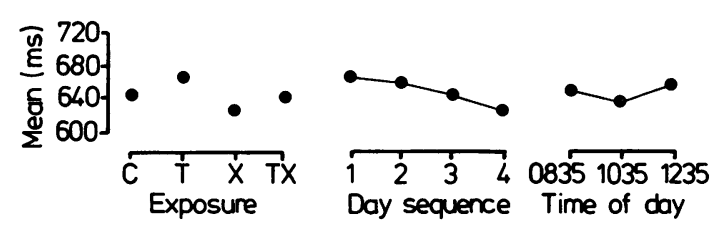

Fig 5 Mean performance in choice reaction time test as a function of exposure, day sequence, and time of day. 
replies, given on seven point scales, clustered round the central value. Ratings of the degree of discomfort, using four verbal alternatives (ranging from no to quite considerable), centred round "negligible."

Immediately after each experimental session, the subjects were asked whether they could identify the condition to which they had been exposed. Most ( 12 of 16) succeeded in identifying the control condition. In other words, the isoamylacetate disguise was successful in only four of 16 cases. Only a few, however, were able to distinguish between the various solvent conditions.

\section{Discussion}

The purpose of the present study was to investigate the possible acute effects on performance of short term exposure to toluene and xylene in concentrations corresponding to the Swedish threshold limit values as well as possible interactive effects of exposure to a combination of both these solvents.

Exposure did not lead to any observable deteriorations of performance in any of the tests used. This applies both to the individual solvents and to the mixture. The absence of manifest effects could be due to the tests used being insufficiently reliable and sensitive. This explanation, however, is not in accordance with the capacity of the tests to show the effects of repeated measurements, which were significant, although small in absolute figures. Moreover, previous studies 251113 showed two of the tests used to be sensitive to the effects of solvents.

Simple reaction time was found to increase for repeated measurements both within and between the experimental days. The analysis of intraindividual variation in the simple reaction time test also indicated successively declining performance when measurements were taken repeatedly during one and the same experimental day. On the other hand, there were no significant differences due to the sequence of experimental days. The deterioration of mean values and the increasing intraindividual variation in the simple reaction time test were probably due to mental fatigue or diminishing motivation on the part of the subjects.

Performance in the memory test improved significantly both within and between experimental days when the analysis was based on the number of correctly reproduced elements. Here, in other words, there was an obvious learning effect. Since the specific content of the items of this test varied from one testing occasion to another, the subjects probably learnt a strategy for dealing with tasks of this type. It was also obvious that the amount of training (two tests on the day preceding the first session) was insufficient for the subjects to achieve a stable level of performance. Stability in this respect is desirable when repeated measurements are taken and training is therefore necessary. The amount of training, however, has to be gauged carefully, so that performance will not deteriorate as a result of growing mental fatigue or diminishing motivation as might have been the case with the simple reaction time test.

In the choice reaction time test performance tended to improve from one experimental day to another, since reaction times gradually diminished. The improvement, however, was not significant. On the other hand, the level of difficulty did have a significant effect within the test, in such a way that reaction time increased as the task became more difficult. The position of the critical stimulus was also found to be significantly related to performance, in such a way that reaction time was longer for stimuli pointing downwards and to the right.

The different performance tests activated the subjects to varying degrees, as was shown by heart rate measurements in the course of the various tests. As in our previous studies on solvents ${ }^{26}$ the level of arousal as measured by heart rate appeared to be a function of the complexity of the performance test. Thus the highest heart rate occurred during the memory test whereas the lowest heart rate was obtained during the simple reaction time test.

The absence of observable effects of exposure on performance in the present experiment should not be interpreted as conflicting with the positive results obtained in previous studies. In these earlier studies $^{17-20}$ the exposure levels were generally higher, and in two cases the experimental condition also included physical work as a means of increasing solvent uptake.

In an investigation of workers occupationally exposed to toluene Iregren found a decrement in simple reaction time, which he interpreted as due to a reversible acute effect of exposure. ${ }^{13}$ The exposure levels in that study were probably about the same as in the present investigation, but the workers were exposed for a longer period (6-8 hours). In the present experiment the subjects were healthy young men who had not been occupationally exposed to solvents. Some caution should therefore be exercised in generalising these results to heterogenous populations of occupationally exposed workers. Furthermore, this study refers only to acute exposure, and it is not possible on the strength of these negative results to make any pronouncements concerning the risk of long term effects.

The fact that exposure to a combination of the two solvents could not be shown to have any effects does not entirely exclude the possibility of such 
effects resulting from exposure to higher concentrations than those used here. It is also important to point out that in the previous investigations, where combination effects were observed, solvents from completely different groups of substances, were used including styrene and trichlorethylene, ${ }^{16}$ ethanol and xylene, ${ }^{23}$ and ethanol and trichlorethylene. ${ }^{22}$ Toluene and xylene, used in the present study, are both aromatic hydrocarbons.

To summarise, the present investigation failed to find any effect on behavioural performance after exposure for four hours to toluene, xylene, and a combination of the two solvents in concentrations corresponding to the Swedish threshold limit values. The adequacy of these norms in preventing acute effects on the central nervous system cannot, therefore, be questioned on the basis of the present study.

\section{References}

' Anshelm Olson B, Gamberale F, Grönqvist B. Reaction time among steel workers exposed to solvent vapors. A longitudinal study. Int Arch Occup Environ Health 1981;48:211-8.

${ }^{2}$ Anshelm Olson B. Effects of organic solvents on behavioral performance of workers in the paint industry. Neurobehav Toxicol Teratol 1982;4:703-8.

${ }^{3}$ Axelson O, Hane M, Hogstedt C. A case referent study on neuropsychiatric disorders among workers exposed to solvents. Scand J Work Environ Health 1976;2:14-20.

${ }^{4}$ Cherry N, Waldron HA, Wells GG, Wilkinson RT, Wilson HK, Jones S. An investigation of the acute behavioural effects of styrene on factory workers. $\mathrm{Br} J$ Ind Med 1980;37:234-40.

${ }_{5}$ Gamberale F, Lisper H-O, Anshelm Olson B. The effects of styrene vapors on the reaction time of workers in the plastic boat industries. In: Horvath M, ed. Adverse effects of envrionmental chemicals and psychotropic drugs. Vol 2. Amsterdam: Elsevier Scientific Publishing Co 1976:135-48.

- Götell P, Axelson O, Lindelöf B. Field studies on human styrene exposure. Work Environment Health 1972;9:76-83.

' Hane M, Axelson O, Blume J, Hogstedt C, Sundell L, Ydreborg B. Psychological function changes among house painters. Scand J Work Environ Health 1977;3:91-9.

${ }^{8}$ Knave B, Anshelm Olson B, Elofsson S, et al. Long-term exposure to jet fuel. II. A cross-sectional epidemiologic investigation on occupationally exposed industrial workers with special reference to the nervous system. Scand J Work Environ Health 1978;4:19-45.

${ }^{9}$ Lindström K. Psychological performance of workers exposed to various solvents. Work Environment Health 1973;10:151-5.

${ }^{10}$ Lindström PK, Härkönen $\mathrm{H}$, Hernberg S. Disturbances in psychological functions of workers occupationally exposed to styrene. Scand J Work Environ Health 1976;3:129-39.

" Elofsson S-A, Gamberale F, Hindmarsh T, et al. Exposure to organic solvents. A cross-sectional epidemiologic investigation on occupationally exposed car and industrial spray painters with special reference to the nervous system. Scand J Work Environ Health 1980;6:239-70.

${ }^{12}$ Hänninen H, Eskelinen L, Husman K, Nurminen M. Behavioral effects of long-term exposure to a mixture of organic solvents. Scand J Work Environ Health 1976;4:240-55.

${ }^{13}$ Iregren A. Effects on psychological test performance of workers exposed to a single solvent (toluene) - a comparison with effects of exposure to a mixture of organic solvents. Neurobehav Toxical Teratol 1982;4:695-701.

${ }^{14}$ Ikeda M, Ohtsuji H. Phenobarbital-induced protection against toxicity of toluene and benzene in the rat. Toxicol Appl Pharmacol 1971;20:30-43.

is Sedivec V, Flek J. The absorption, metabolism and excretion of xylenes in man. Int Arch Occup Environ Health 1976;37:205-17.

16 Ödkvist LM, Larsby B, Fredrickson JMF, Liedgren SRC, Tham R. Vestibular and oculomotor disturbances caused by industrial solvents. J Otolaryngol 1980;9:53-9.

$"$ Gamberale F, Hultengren M. Toluene exposure: II. Psychophysiological functions. Work Environment Health 1972;9:131-9.

${ }^{18}$ Gamberale F, Annwall G, Hultengren M. Exposure to xylene and ethylbenzene: III. Effects on central nervous functions. Scand J Work Environ Health 1978;4:204-11.

19 Savolainen K, Riihimäki V, Linnoila M. Effects of short-term xylene exposure on psychophysiological functions in man. Int Arch Occup Environ Health 1979;44:201-11.

${ }^{20}$ Savolainen K, Riihimäki V, Seppäläinen AM, Linnoila M. Effects of short-term xylene exposure and physical exercise on the central nervous system. Int Arch Occup Environ Health 1980;45: 105-21.

${ }^{21}$ Savolainen K, Riihimäki V, Laine A, Kekoni J. Short-termco exposure of human subjects to $\mathrm{M}$-xylene and $1,1,1-$ tricholoroethane. Int Arch Occup Environ Health 1981;49:89-98.

${ }^{22}$ Windemüller FJB, Ettema JH. Effects of combined exposure to trichlorethylene and alcohol on mental capacity. Int Arch Occup Environ Health 1978;41:77-85.

${ }^{23}$ Savolainen K. Combined effects of xylene and alcohol on the central nervous system. Acta Pharmacol Toxicol 1980;46:366-72.

${ }^{24}$ Söderman E, Kjellberg A, Anshelm Olson B, Iregren A. Standardization of a simple reaction time test for behavioral toxicology investigations. Undersökningsrapport 1982;27, National Board of Occupational Safety and Health, Solna, Sweden. (In Swedish.)

${ }^{25}$ Wiener BJ. Statistical principles in experimental design. New York: McGraw Hills, 1970.

${ }^{26}$ Gamberale F. Behavioral effects of exposure to solvent vapors: experimental and field studies. In: Horvath $\mathrm{M}$, ed. Adverse effects of environmental chemicals and psychotropic drugs. Vol 2. Amsterdam: Elsevier Scientific Publishing Co, 1976:11133. 